\title{
Loss of Rb1 by epigenetic modification regulates expansion of MDSC in cancer
}

\author{
Je-In Youn ${ }^{1 *}$, Kyungwha Lee ${ }^{1}$, Hai-Chon Lee ${ }^{1}$, Dmitry I Gabrilovich ${ }^{2}$ \\ From Society for Immunotherapy of Cancer 29th Annual Meeting \\ National Harbor, MD, USA. 6-9 November 2014
}

Myeloid-derived suppressor cells (MDSCs) are a heterogeneous group of cells with potent immune suppressive activity in cancer and many other pathologic conditions. MDSCs consist of two major subsets: monocytic MDSCs (M-MDSCs) and polymorphonuclear MDSCs (PMN-MDSCs). Each subset of MDSCs is thought to be developed through the separate differentiation pathways. Here, we demonstrated that in a tumor environment a large proportion of M-MDSCs acquired phenotypic, morphological and functional features of PMN-MDSCs while the normal counterpart of M-MDSCs-Ly6Chi Ly6G $^{-}$inflammatory monocytes (Mon) from tumor-free mice differentiate to macrophages $(M \Phi)$ and dendritic cells (DCs). This process was mediated by loss of the retinoblastoma (Rb1) protein in MDSCs. Inhibition of Rb1 expression in PMN-MDSCs correlated with the level of histone acetylation of Rb1 promoter. Treatment of PMN-MDSCs with inhibitors of histone deacetylases (HDAC) resulted in the increase in Rb1 expression. In addition, inhibition of HDAC abrogated differentiation of M-MDSCs to PMN-MDSCs, and restored M-MDSCs differentiation towards DCs and MФ. These results suggest that down-regulation of Rb1 by epigenetic modification plays a major role in expansion of MDSCs in cancer by regulating PMN-MDSCs differentiation from M-MDSCs. Therefore, inhibition of MDSCs accumulation by treatment of HDAC inhibitors may be considered as a potential therapeutic tool in cancer immunotherapy.

\section{Authors' details}

${ }^{1}$ Wide River Institute of Immunology, Seoul National University, Republic of Korea. ${ }^{2}$ The Wistar Institute, Philadelphia, PA, USA.
Published: 6 November 2014

doi:10.1186/2051-1426-2-S3-P241

Cite this article as: Youn et al.: Loss of Rb1 by epigenetic modification regulates expansion of MDSC in cancer. Journal for ImmunoTherapy of Cancer 2014 2(Suppl 3):P241.
${ }^{1}$ Wide River Institute of Immunology, Seoul National University, Republic of Korea

Full list of author information is available at the end of the article
Submit your next manuscript to BioMed Central and take full advantage of:

- Convenient online submission

- Thorough peer review

- No space constraints or color figure charges

- Immediate publication on acceptance

- Inclusion in PubMed, CAS, Scopus and Google Scholar

- Research which is freely available for redistribution 